\title{
Limited Long-Term Impact of Insect Venom Immunotherapy on the Micro-RNA Landscape in Whole Blood
}

\author{
Karpinski $\mathrm{P}^{1 *}$, Kahraman $\mathrm{M}^{2 *}$, Ludwig $\mathrm{N}^{3}$, Skiba $\mathrm{P}^{1}$, Kosinska $\mathrm{M}^{4}$, Rosiek-Biegus $\mathrm{M}^{4}$, Królewicz $\mathrm{E}^{4}$, \\ Panaszek $B^{4}$, Nittner-Marszalska $\mathrm{M}^{4}$, Blin $\mathrm{N}^{1}$, Keller $\mathrm{A}^{2}$, Meese $\mathrm{E}^{3}$, Sasiadek MM ${ }^{1}$ \\ 'Department of Genetics, Wroclaw Medical University, Wroclaw, Poland \\ ${ }^{2}$ Chair for Clinical Bioinformatics, Saarland University, Saarbrücken, Germany \\ ${ }^{3}$ Institute of Human Genetics, Saarland University, Homburg, Germany \\ ${ }^{4}$ Department and Clinic of Internal Medicine and Allergology, Wroclaw Medical University, Poland \\ *Both authors contributed equally to the manuscript.
}

J Investig Allergol Clin Immunol 2019; Vol. 29(3): 206-212

doi: 10.18176/jiaci.0303

\begin{abstract}
Objective: To perform a genome-wide characterization of changes in microRNA (miRNA) expression during the course of venom immunotherapy (VIT).

Methods: miRNA was isolated from the whole-blood of 13 allergic patients and 14 controls, who experienced no allergic reaction upon stings by honeybees and wasps. We analyzed 2549 miRNAs from the whole blood of these patients prior to VIT and 12 months after the start of VIT. The results for differential expression obtained on a microarray platform were confirmed by quantitative real-time PCR. Out of the 13 patients, 8 had a negative allergic reaction with VIT, thus indicating that this approach was successful.

Results: By comparing time points before and 12 months after ultrarush VIT, correlation analysis and principal component analysis both indicated a limited effect of VIT on the overall miRNA expression pattern. Volcano plot analysis based on raw $P$ values revealed few deregulated miRNAs, most of which were increasingly expressed after VIT as compared with before VIT. Based on the 50 most altered miRNAs, no clear clustering was observed before or after VIT.

Conclusions: Our results indicate an overall reduced effect of VIT on the miRNA expression pattern in whole blood.
\end{abstract}

Key words: miRNA. Whole genome. Blood. Expression. Venom immunotherapy.

\section{Resumen}

Objetivo: Realizar la caracterización genómica de los cambios en la expresión de microARN (miARN) en el curso de ITV (inmunoterapia con veneno).

Métodos: Los microARNs se analizaron en la sangre total de 13 pacientes alérgicos y 14 controles sin reacción alérgica a las picaduras de abejas y avispas. Se analizaron 2549 miRNAs diferentes en la sangre total de estos pacientes antes de la ITV y 12 meses después del inicio de la ITV. Los resultados de expresión diferencial obtenidos en la plataforma de microarrays se confirmaron mediante PCR cuantitativa a tiempo real (qRT-PCR). De los 13 pacientes, se confirmó que ocho tenían una reacción alérgica negativa tras la ITV, lo que indicó una ITV exitosa.

Resultados: Al comparar los resultados de microRNAs, previa IT y 12 meses después de la ITV, la correlación y el análisis de componentes principales indican un efecto limitado de la ITV en el patrón de expresión general de miARN. El análisis de Volcano basado en los valores de P crudos, reveló la existencia de pocos miRNAs desregulados estando la mayoría de ellos sobre-expresados tras la ITV en comparación con la previa. Utilizando los 50 miRNAs que más se alteraban, no se observó una agrupación clara en función del tiempo, es decir, pre y post-ITV. Conclusiones: Nuestros resultados indican que la ITV tiene poco efecto en el patrón de expresión de miARN en sangre completa.

Palabras clave: miARN. Genoma completo. Sangre. Expresión. Inmunoterapia con veneno. 


\section{Introduction}

Stings by hymenoptera, including honeybees and wasps, may cause systemic allergic reactions, which occur with an estimated prevalence of $1 \%-5 \%$ in Europe [1]. Venom immunotherapy (VIT) is a frequently used approach to effectively prevent further severe allergic reactions to insect stings in people who have previously experienced such a complication [2-4]. While a number of immunologic alterations have been well characterized in the context of VIT, the underlying changes in gene expression and their relationship with the overall effectiveness of VIT remain unclear [5]. Recently, microarrays were used to identify venom allergyassociated modification of gene expression in peripheral blood, even though peripheral blood is a heterogeneous mixture of various cell types [6-8]. The main goals in research on genomewide gene expression are to understand molecular triggers for venom allergy and to identify the immunological pathways that are responsible for an effective response to VIT [9]. In the last decade, microRNAs (miRNAs) have emerged as key regulators of diverse biological and pathological processes (eg, carcinogenesis, morphogenesis, apoptosis, and cell differentiation) in several human tissues [10-13]. miRNAs are small, single-stranded, noncoding RNAs that anneal to the 3'-UTR of target mRNAs to downregulate gene expression by inhibiting translation or stimulating mRNA degradation [14-17]. The involvement of miRNAs in various human diseases makes them promising novel targets of research and provides insights into the

Table 1. Demographic and Clinical Data

\begin{tabular}{|c|c|c|c|c|c|c|c|c|c|c|}
\hline $\begin{array}{l}\text { Patient's } \\
\text { Number }^{\mathrm{a}}\end{array}$ & Age & Gender & $\begin{array}{l}\text { Grade of } \\
\text { Reaction }^{\text {b }}\end{array}$ & $\begin{array}{c}\text { Responsible } \\
\text { Insect }\end{array}$ & $\begin{array}{l}\text { Concentration } \\
10-^{6} \mathrm{~g} / \mathrm{L}, \mathrm{mm}^{\mathrm{c}}\end{array}$ & $\begin{array}{c}\text { sIgE, } \\
\text { Concentration }^{\mathrm{d}} \\
(\text { Class })\end{array}$ & $\begin{array}{c}\text { Vesp v } 1 \\
\text { Concentration } \\
\quad(\text { Class })\end{array}$ & $\begin{array}{c}\text { Vesp v } 5 \\
\text { Concentration } \\
\text { (Class) }\end{array}$ & $\begin{array}{c}\text { Api m } 1 \\
\text { Concentration } \\
\text { (Class) }\end{array}$ & Result \\
\hline $11 \mathrm{~A} / 11 \mathrm{C}$ & 45 & $\mathrm{~F}$ & III & Wasp & $12 \times 12$ & $12.13(2)$ & $0.02(0)$ & $6.82(3)$ & $0.002(0)$ & Negative \\
\hline $6 \mathrm{~A} / 6 \mathrm{C}$ & 32 & M & IV & Wasp & $9 \times 11$ & $2.23(2)$ & $0.03(0)$ & $10.4(3)$ & $0.01(0)$ & Negative \\
\hline $2 \mathrm{~A} / 2 \mathrm{C}$ & 45 & M & IV & Wasp & $10 \times 10$ & 0.589 (1) & 0.07 (1) & $0.33(0)$ & $0(0)$ & Negative \\
\hline $7 \mathrm{~A} / 7 \mathrm{C}$ & 40 & M & IV & Wasp & $11 \times 14$ & 9.15 (3) & 11.4 (3) & $0.28(0)$ & $0(0)$ & Negative \\
\hline $19 \mathrm{~A} / 19 \mathrm{C}$ & 37 & M & IV & Wasp & $8 \times 11$ & $1.86(2)$ & ND & ND & ND & Negative \\
\hline $15 \mathrm{~A} / 15 \mathrm{C}$ & 40 & $\mathrm{~F}$ & III & Wasp & $10 \times 12$ & $7.59(3)$ & $0.61(1)$ & 3.47 (2) & $0(0)$ & Negative \\
\hline $13 \mathrm{~A} / 13 \mathrm{C}$ & 50 & $\mathrm{~F}$ & IV & Wasp & $10 \times 11$ & $5.11(3)$ & $1.96(2)$ & $4.88(3)$ & 0.37 (1) & ND \\
\hline $16 \mathrm{~A} / 16 \mathrm{C}$ & 62 & M & III & Bee & $13 \times 16$ & $8.96(3)$ & ND & ND & ND & Negative \\
\hline $1 \mathrm{~A} / 1 \mathrm{C}$ & 38 & $\mathrm{~F}$ & IV & Wasp & $7 \times 9$ & $5.2(3)$ & $0.01(0)$ & $3.12(2)$ & $0.004(0)$ & ND \\
\hline $14 \mathrm{~A} / 14 \mathrm{C}$ & 62 & $\mathrm{~F}$ & IV & Wasp & $8 \times 10$ & $0.35(0)$ & $0.003(0)$ & $1.59(2)$ & $0(0)$ & ND \\
\hline $18 \mathrm{~A} / 18 \mathrm{C}$ & 56 & $\mathrm{~F}$ & IV & Wasp & $7 \times 8$ & $2.15(2)$ & ND & ND & ND & Negative \\
\hline $17 \mathrm{~A} / 17 \mathrm{C}$ & 71 & M & III & Bee & $10 \times 12$ & $5.61(3)$ & $0(0)$ & $0(0)$ & $0.12(0)$ & ND \\
\hline $13 \mathrm{~A} / 13 \mathrm{C}$ & 52 & $\mathrm{~F}$ & III & Wasp & $10 \times 11$ & $1.11(3)$ & $10.96(2)$ & $1.88(3)$ & $0.67(0)$ & ND \\
\hline $10 \mathrm{G}$ & 23 & M & Nonallergic & ND & ND & ND & ND & ND & ND & ND \\
\hline $11 \mathrm{G}$ & 22 & M & Nonallergic & ND & ND & ND & ND & ND & ND & ND \\
\hline $12 \mathrm{G}$ & 25 & M & Nonallergic & ND & ND & ND & ND & ND & ND & ND \\
\hline $13 \mathrm{G}$ & 31 & $\mathrm{~F}$ & Nonallergic & ND & ND & ND & ND & ND & ND & ND \\
\hline $14 \mathrm{G}$ & 22 & M & Nonallergic & ND & ND & ND & ND & ND & ND & ND \\
\hline $1 \mathrm{G}$ & 33 & M & Nonallergic & ND & ND & ND & ND & ND & ND & ND \\
\hline $2 \mathrm{G}$ & 27 & M & Nonallergic & ND & ND & ND & ND & ND & ND & ND \\
\hline $3 \mathrm{G}$ & 29 & $\mathrm{~F}$ & Nonallergic & ND & ND & ND & ND & ND & ND & ND \\
\hline $4 \mathrm{G}$ & 26 & $\mathrm{~F}$ & Nonallergic & ND & ND & ND & ND & ND & ND & ND \\
\hline $5 \mathrm{G}$ & NA & $\mathrm{F}$ & Nonallergic & ND & ND & ND & ND & ND & ND & ND \\
\hline $6 \mathrm{G}$ & 60 & $\mathrm{~F}$ & Nonallergic & ND & ND & ND & ND & ND & ND & ND \\
\hline $7 \mathrm{G}$ & 18 & M & Nonallergic & ND & ND & ND & ND & ND & ND & ND \\
\hline $8 \mathrm{G}$ & 62 & $\mathrm{~F}$ & Nonallergic & ND & ND & ND & ND & ND & ND & ND \\
\hline $9 \mathrm{G}$ & 28 & $\mathrm{~F}$ & Nonallergic & ND & ND & ND & ND & ND & ND & ND \\
\hline
\end{tabular}

Abbreviations: IDT, intradermal test; ND, not determined; slgE, specific lgE.

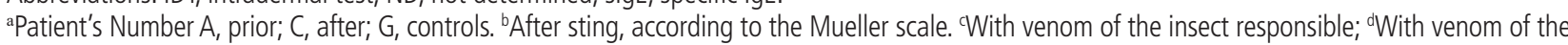
insect responsible; eSting challenge/field sting. 
molecular mechanisms of and potential therapeutic approaches in human malignancies [15]. Previous reports implicated miRNAs in the pathogenesis of several allergic diseases including asthma, food allergy, eosinophilic esophagitis, allergic rhinitis, and atopic dermatitis [18]. A recent study of 740 miRNAs revealed changes in miRNA expression in the build-up phase of hymenoptera VIT [19]. We studied the longterm effects of hymenoptera VIT by measuring the abundance of 2549 miRNAs before and 1 year after initiation of VIT.

\section{Materials and Methods}

\section{Study Group}

The group of patients selected for miRNA expression microarray analysis consisted of 13 patients with severe allergic reactions (III/IV according to the Mueller classification) after bee or wasp sting (Vespula species). Patients were recruited from the Department and Clinic of Internal Medicine and Allergology, Wroclaw Medical University, Poland. Fourteen individuals with no allergic reactions after bee or wasp stings were included as a control group. The study was approved by the Wroclaw Medical University Ethics Committee (internal number 521/2012). All patients gave their informed consent to participate in the study. Blood from each patient was sampled twice (before and after 1 year of VIT). Detailed characteristics of individuals recruited to this study are presented in Table 1.

\section{Ultrarush Hymenoptera Venom Immunotherapy Protocol}

Ultrarush hymenoptera venom immunotherapy was administered in the same way for all study patients. Treatment began with an initial venom dose of $0.1 \mu \mathrm{g}$; the cumulative dose of $111.1 \mu \mathrm{g}$ was reached within 3.5 hours. A venous access with infusion of saline solution $0.9 \%$ was secured before the first injection. Standardized lyophilized venom allergen extract (Pharmalgen, ALK-Abelló) was used for the build-up phase, and aluminum hydroxide-adsorbed insect venom (Alutard, ALKAbelló) was used for the maintenance phase.

\section{MiRNA Isolation and Microarray Hybridization}

Whole blood samples were collected in PAXgene Blood RNA Tubes (BD Biosciences) and stored at $-60^{\circ} \mathrm{C}$. Total RNA containing miRNA was isolated using the PAXgene Blood miRNA Kit (Qiagen). miRNA abundances were analyzed using an miRNA expression array (SurePrint G3 Unrestricted miRNA 8x60K v21, Agilent Technologies) encompassing 2549 known human miRNAs. All procedures were carried out according to the manufacturer's recommendations. To generate fluorescently labeled RNAs, $100 \mathrm{ng}$ of total RNA per sample was processed by the miRNA Complete Labeling and Hyb Kit (Agilent Technologies). Samples were loaded onto the microarrays and incubated at $55^{\circ} \mathrm{C}$ for 20 hours with rotation. Subsequent to washing, microarrays were scanned with the Agilent Microarray Scanner at $3 \mu$ in double-path mode. Data were acquired using Agilent AGW Feature Extraction software version 10.10.11 (Agilent Technologies).

\section{Real-time Quantitative Reverse Transcription-PCR Analysis}

Expression levels of 2 miRNAs that displayed significant deregulation in CD8 T cells were analyzed on the prepared cDNA using the miScript II RT Kit according to the manufacturer's recommendations (Qiagen). Amplification was detected with $5 \mathrm{ng}$ of cDNA on a LightCycler480 instrument (Roche, USA) using the miScript Starter PCR Kit (Qiagen) and miRNA specific quantitative RT-PCR primer sets for the miRNA of interest (Qiagen: hsa-miR-16-2 [cat. no: MS00008813] and hsa-miR-4516 [cat. no: MS00037555], and endogenous control RNU6-2 [included in the miScript Starter PCR Kit]). Each qRT-PCR reaction was conducted in duplicate.

\section{Statistical Analysis}

We used the statistical program R v.3.4.0 to analyze differences in miRNA abundance between VIT patients. After applying the Feature Extraction software (Agilent Technologies), we computed the normalized total gene signal for each miRNA using the robust multiarray average method (AgiMicroRna) based on quantile normalization [20]. The resulting expression values were transformed to log (base 2). The whole miRNA set of 2549 miRNAs was then reduced to 534 by filtering in such a way that each marker was detected in at least $25 \%$ of the samples in 1 of the 3 groups (before, after, and controls). Different levels of miRNAs among the same probands before and after the wasp sting were analyzed using a paired 2-tailed $t$ test. We used a hierarchical clustering approach with the 50 most altered miRNAs (as revealed by raw $P$ values) to detect clusters of miRNAs and blood samples. We applied bottom-up complete linkage clustering and used the Euclidian distance measure. In addition, we carried out a standard principal component analysis and provide scatter plots of the first and the second principal components [21]. Relative quantification of miRNA expression and calculation of the confidence interval were performed using REST 2009 [22].

\section{Computation of Blood Cell-Specific Differential Expression}

Relative blood cell proportions were computed using normalized gene expression data obtained from the same patients on the Affymetrix PrimeView platform (results to be published, raw data available from Geo Expression Omnibus: GSE92866). After data normalization, we applied the CIBERSORT algorithm (1000 iterations) and LM22 gene signature to predict relative proportions of 9 major cell types (B cells, CD8 T cells, CD4 T cells, regulatory T cells, NK cells, monocytes, macrophages, dendritic cells, and neutrophils) [23]. The proportions calculated were used as an input for the csSAM package, which enables the analysis of differential expression for each blood cell type [24].

\section{Results}

The aim of the study was to provide a comprehensive comparison of miRNAs derived from the whole blood of patients before and 12 months after the start of VIT treatment. 


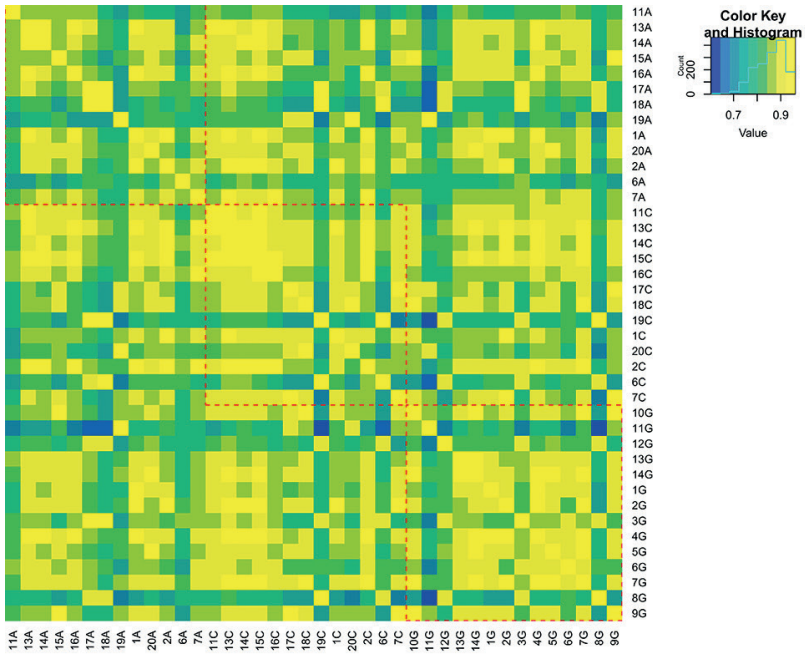

Figure 1. Correlation matrix. A pairwise Pearson correlation coefficient of the miRNA expression profile was computed for all samples. Yellow to blue colors indicate high or low correlation coefficient values. The numbers indicate the different individuals. A and $\mathrm{C}$ denote the time points of blood collection before and after VIT, respectively. Controls are indicated by G.

In total, we compared the abundance of 2549 miRNAs from 13 patients ( 6 males and 7 females), each of whom had had severe allergic reactions (grades III or IV in the Mueller classification) after bee or wasp stings. Detailed clinical characteristics of the patients are given in Table 1. Eight of the 13 patients were challenged with insect venom after finishing therapy; the results were negative for signs of allergy to hymenoptera venom in all 8 patients, indicating that VIT was successful. The control group ( 7 males and 7 females) consisted of individuals who did not experience allergic reactions after a bee or wasp sting (as revealed by skin prick testing).

A

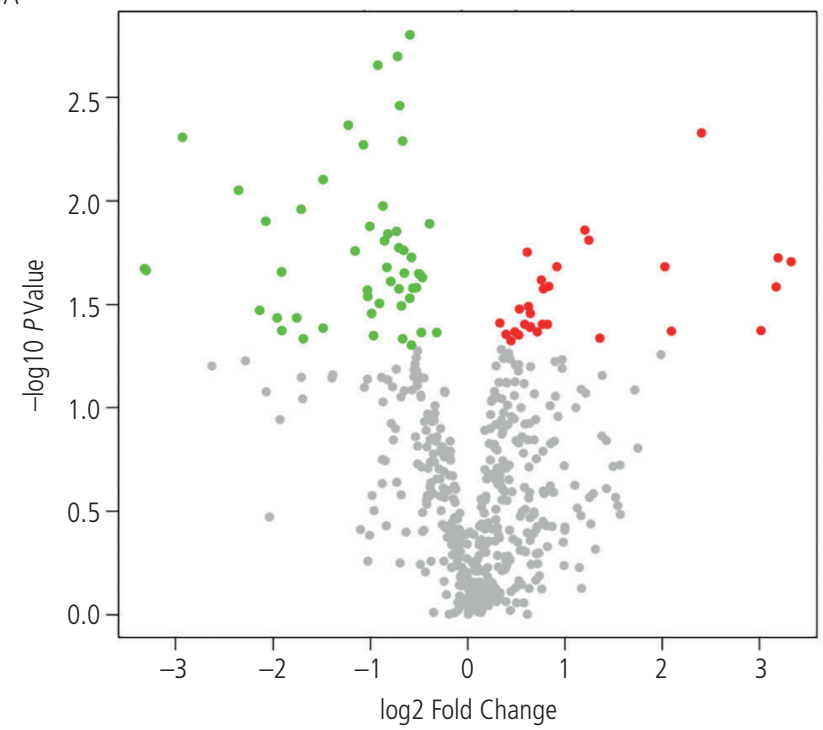

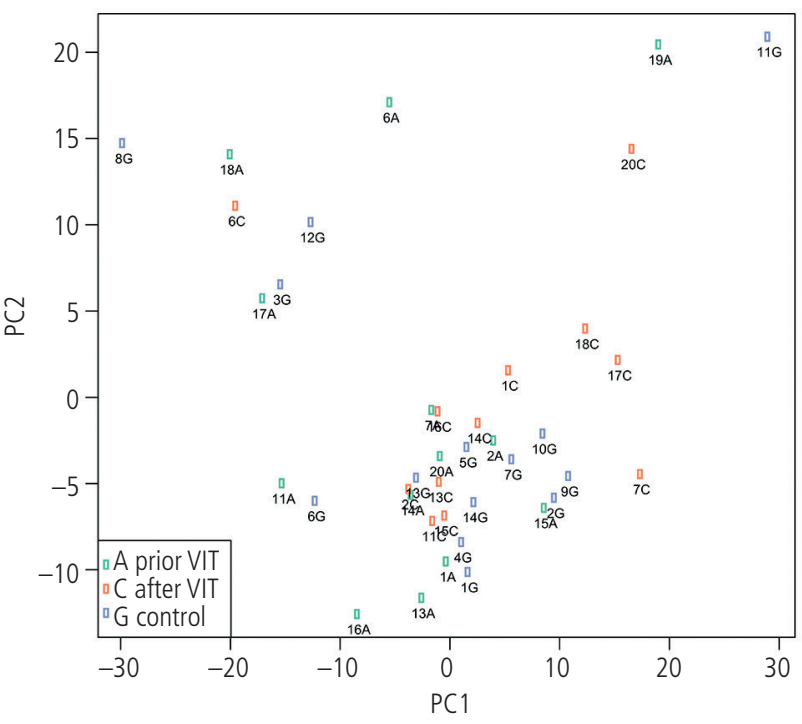

Figure 2. Principal component analysis. Principal component analysis of blood samples taken from patients before VIT and 12 months after VIT. The figure shows the first principal component (PC1) on the $x$-axis and the second PC2 on the y-axis. The numbers indicate the different patients. A and $\mathrm{C}$ denote the time points of blood collection before VIT (green) and after VIT (orange), respectively. Controls are indicated in blue and by G.

We first compared the individuals tested based on the overall miRNA expression pattern. Analysis of the correlation between the samples revealed a reduced correlation in several samples (Figure 1). Principal component analysis showed no signs of difference between the time points before and 12 months after VIT (Figure 2). As for specific miRNAs with abundances altered by VIT, volcano plot analysis based on raw $P$ values revealed few deregulated miRNAs, with most of

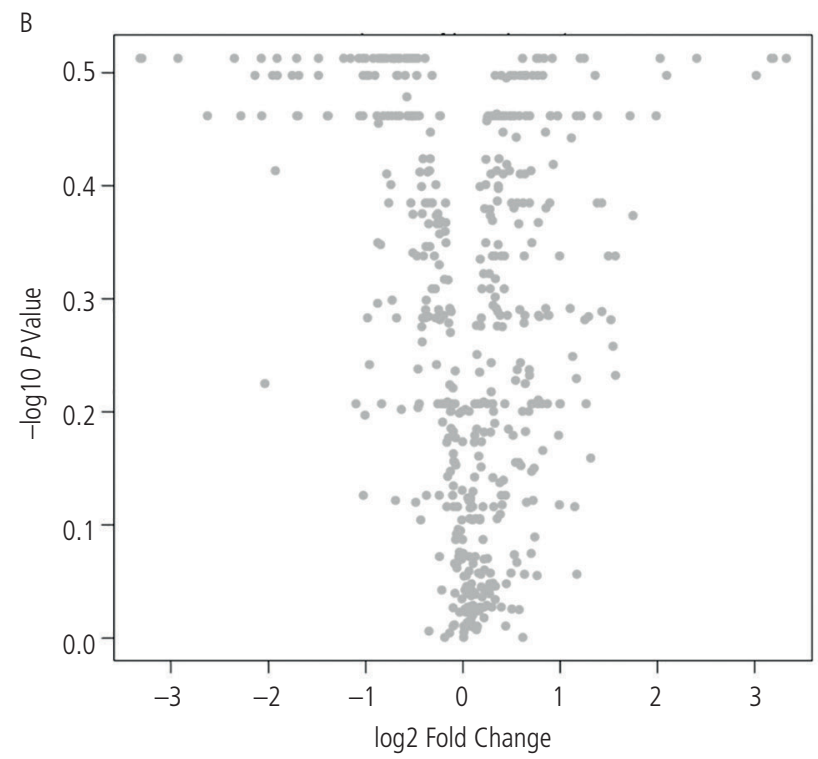

Figure 3. Differential expression of miRNAs upon VIT. A, Analysis based on raw values. B, Data after adjustment of $P$ value for multiple testing. Volcano plots of all measured bloodborne miRNAs show the fold change of each miRNA on a logarithmic scale (base 2 ) on the $x$-axis and the negative logarithmic $P$ value (base 10) on the $y$-axis. The miRNA significantly overexpressed before VIT compared with after VIT are indicated as red dots. miRNAs with significantly lower expression before VIT are indicated as green dots. 


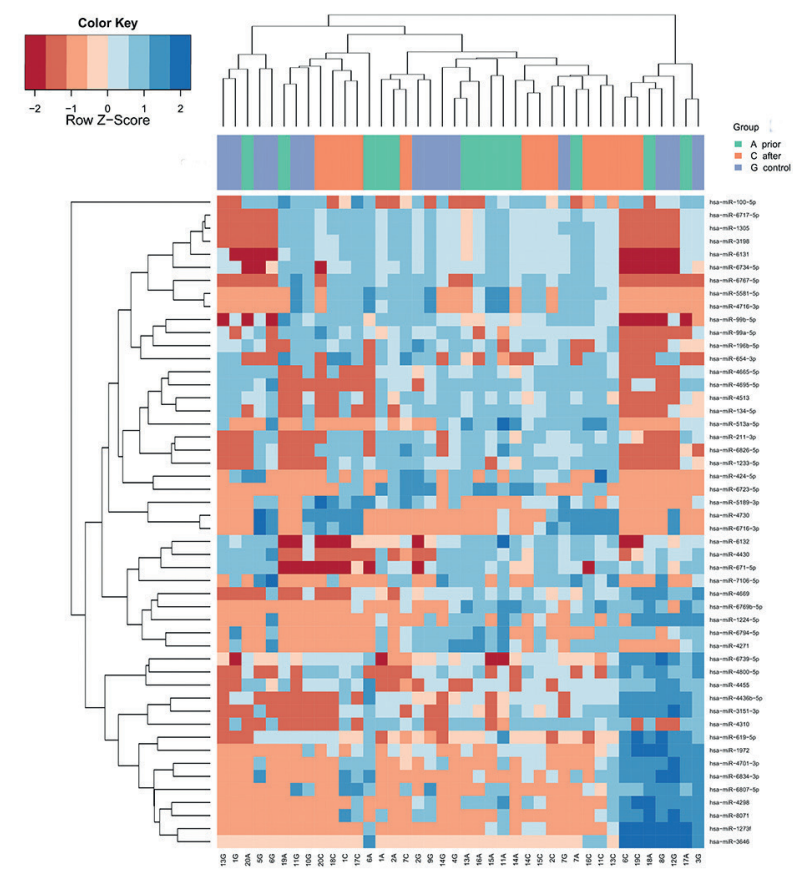

Figure 4. Hierarchical clustering of samples before (green) and 12 months after the start of VIT (orange) based on the 50 most altered miRNAs. Controls are indicated in blue. Samples belonging to the same individual are indicated at the bottom of the heat map; miRNAs used for the heat map are indicated on the right-hand side.

them displaying a lower abundance level prior to VIT than after VIT (Figure 3A). After adjustment of the $P$ value, the volcano blot analysis did not indicate any miRNA with a significantly altered abundance between the time points before and after VIT (Figure 3B). These results also point to an overall low effect of VIT on the miRNA expression pattern in whole blood. Figure 4 presents the results of the analysis of variance between both time points and the controls for the 50 most altered miRNAs.

Based on the differences in miRNA abundance between the time points before and after VIT, we performed a cluster analysis using the 50 most altered miRNAs. Figure 4 shows the lack of clustering between 2 time points before and after VIT. These data further indicate a rather limited impact of ultrarush VIT on the miRNA expression pattern in blood.

Finally, we computed the differential expression for each blood cell type between 2 time points (before and after VIT). Applying this approach, we found 14 miRNAs (4 downregulated/10 upregulated) with a differential abundance in CD8 T lymphocytes and 2 differentially expressed miRNAs in monocytes (adjusted $P$ value $\leq .25$ as proposed by the authors of csSAM [24] (Table 2). Subsequently, we selected

Table 2. Differentially Regulated miRNAs in Blood Cell Types

\begin{tabular}{lccc}
\hline CD8 T & Status & $\begin{array}{c}\text { Expression } \\
\text { Difference }^{\mathrm{a}}\end{array}$ & $\begin{array}{c}\text { FDR }^{\mathrm{b}} \\
(P \text { Value })\end{array}$ \\
\hline hsa-miR-16-2-3p & Downregulated & -3.66 & 0.21 \\
hsa-miR-371b-5p & Upregulated & 3.19 & 0.21 \\
hsa-miR-3960 & Upregulated & 4.44 & 0.21 \\
hsa-miR-4286 & Downregulated & -3.41 & 0.21 \\
hsa-miR-4466 & Upregulated & 3.00 & 0.24 \\
hsa-miR-4516 & Upregulated & 3.91 & 0.21 \\
hsa-miR-4763-3p & Upregulated & 3.32 & 0.21 \\
hsa-miR-6089 & Upregulated & 3.54 & 0.21 \\
hsa-miR-638 & Upregulated & 3.17 & 0.21 \\
hsa-miR-664a-3p & Downregulated & -3.21 & 0.21 \\
hsa-miR-6803-5p & Upregulated & 3.26 & 0.21 \\
hsa-miR-6826-5p & Downregulated & -3.08 & 0.23 \\
hsa-miR-7108-5p & Upregulated & 3.92 & 0.21 \\
hsa-miR-8063 & Upregulated & 3.27 & 0.21 \\
Monocytes & & & \\
hsa-miR-6785-5p & Upregulated & 4.89 & 0.23 \\
hsa-miR-494-3p & Upregulated & 4.39 & 0.23 \\
\hline
\end{tabular}

${ }^{\mathrm{a}}$ Expression difference $=$ after - before

bFDR cut-off $\leq 0.25$
A

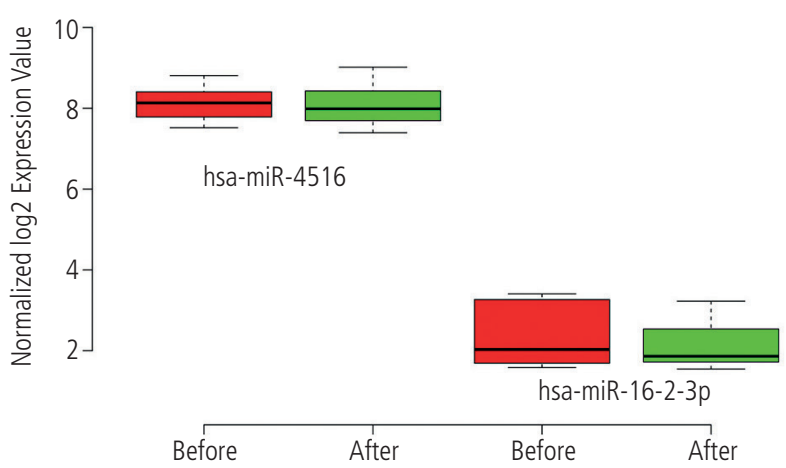

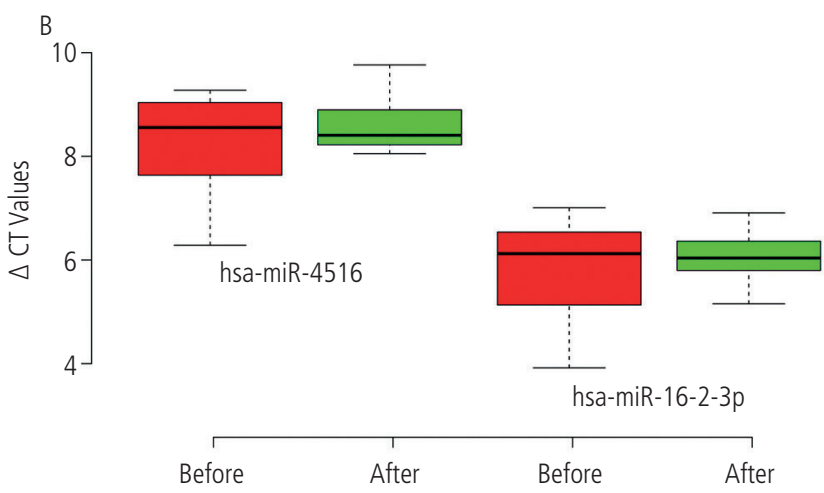

Figure 5. Expression of 2 selected miRNA before and after VIT. A, Derived from the array-based approach. B, Derived from RT-qPCR. Box-whisker plots of miRNAs differentially expressed in the blood of patients before VIT (red) and 12 months after VIT (green). The boxes represent the second and third quartiles; the whiskers represent the minimum and maximum expression values. miRNAs were selected based on significant deregulation in CD8 T cells (see Table 2). 
two miRNAs based on significant deregulation in CD8 T cells (hsa-miR-16-2-3p and hsa-miR-4516) to perform qRT-PCR in whole blood (Figure 5). A comparison of the study groups revealed no significant alterations in the selected miRNAs (before and after VIT).

Functional enrichment of genes targeted by up- or downregulated miRNAs revealed a number of significantly deregulated pathways, although none of these could be attributed to immunology- or allergy-related mechanisms (data not shown).

\section{Discussion}

Various changes in miRNA expression were recently identified in the build-up phase of hymenoptera VIT after screening 740 miRNAs [19]. Here, we studied the long-term effects of hymenoptera VIT by measuring the abundances of 2549 miRNAs 1 year after initiation of VIT. While we found a limited effect on the overall miRNA expression pattern, we detected few miRNAs that displayed an altered expression pattern 1 year after VIT. The influence of VIT was sufficient to prevent clustering of 2 samples from a given patient.

The difference between our results and those reported by Specijalski et al [19] in 2016 can be explained by the time points taken for the build-up phase of immunotherapy: measurement of miRNA changes 24 hours after VIT instead of 12 months, as in our study. Further differences between the studies include the mode of blood sampling (PAXgene vs conventional blood collection), the number of miRNAs analyzed (2549 miRNAs vs 740 miRNAs), and the different methods used (array-based approach vs qRT-PCR). Bearing these facts in mind, the comparison of both studies indicates that the long- and short-term effects of VIT on the miRNA pattern appear to be different. After 12 months of VIT, the pattern of miRNA expression in whole blood was largely similar to that observed before VIT.

As in numerous previous studies, we used the PAXGene system, which enables immediate stabilization of intracellular RNA, thereby facilitating the generation of reproducible miRNA expression data. A drawback of this approach is that lysis of blood prevents us from associating the identified miRNA pattern with specific blood cells. In addition, even experimental cell sorting does not necessarily enable us to detect the miRNA pattern of specific cell types owing to the stress effects on expression patterns, as previously described by our group and other authors $[25,26]$. We addressed this problem by testing a deconvolution algorithm that makes it possible to predict differently expressed miRNAs in small cell subpopulations [27]. Using the deconvolution algorithm, we predicted the miRNA abundance in B cells, CD8 T cells, CD4 $\mathrm{T}$ cells, regulatory $\mathrm{T}$ cells, NK cells, monocytes, macrophages, dendritic cells, and neutrophils. We found a differential abundance in 14 miRNAs in CD8 T lymphocytes and in 2 miRNAs in monocytes. The elevated number of miRNAs predicted to be deregulated in $\mathrm{T}$ cells is consistent with findings from previous studies, suggesting that biochemical changes in $\mathrm{CD}^{+} \mathrm{T}$-cell function may represent key events in successful T-cell immunotherapy [28]. As for the function of monocytes during VIT, there is less evidence linking changes in miRNA abundance to VIT. Although the deconvolution algorithm used indicates differently expressed miRNAs in blood cell subpopulations, the influence of VIT on cell type-specific miRNA changes awaits experimental validation.

A potential limitation of our study is the fact that that whole blood was used as the miRNA source, whereas significant changes in expression resulting from VIT revealed by the deconvolution approach were specific to a small fraction of cells (eg, CD8 T cells). The presence of a large proportion of cells that do not provide useful information on the patient's condition in the context of VIT (eg, neutrophils) may weaken cell-specific expression signals.

In summary, we studied the influence of hymenoptera VIT on miRNA abundance in the whole blood of hymenoptera venom-allergic patients and found evidence for changes in the expression of specific miRNA in whole blood before and 1 year after initiation of VIT. The overall miRNA pattern was, however, largely unaffected. Our results pave the way for further study of the role of miRNA-based regulation during the process of desensitization, including cell type-specific alteration of miRNA abundances.

\section{Acknowledgments}

The authors would like to thank all the patients who participated in this study.

\section{Funding}

This study was supported by the Polish National Science Centre (NCN), grant 2012/05/B/NZ6/00637 (2013-2016).

\section{Conflicts of Interest}

The authors declare that they have no conflicts of interest.

\section{References}

1. Alfaya Arias T, Soriano Gómis V, Soto Mera T, Vega Castro A Vega Gutiérrez JM, Alonso Llamazares A, et al. Key Issues in Hymenoptera Venom Allergy: An Update. J Investig Allergol Clin Immunol. 2017;27(1):19-31.

2. Nittner-Marszalska M, Liebhart J, Liebhart E, Dor A, Dobek $R$, Obojski $A$, et al. Prevalence of Hymenoptera venom allergy and its immunological markers current in adults in Poland. Med Sci Monit. 2004;10(7):CR324-9.

3. Aeberhard J, Haeberli G, Müller UR, Helbling A. Specific Immunotherapy in Hymenoptera Venom Allergy and Concomitant Malignancy: A Retrospective Follow-up Focusing on Effectiveness and Safety. J Investig Allergol Clin Immunol. 2017;27(6):370-7.

4. Sturm GJ, Varga EM, Roberts G, Mosbech H, Bilò MB, Akdis $C A$, et al. EAACl guidelines on allergen immunotherapy: Hymenoptera venom allergy. Allergy. 2018;73(4):744-64.

5. Akdis M, Akdis CA. Mechanisms of allergen-specific immunotherapy: multiple suppressor factors at work in immune tolerance to allergens. J Allergy Clin Immunol. 2014;133(3):621-31.

6. Niedoszytko M, Bruinenberg M, de Monchy J, Wijmenga C, Platteel M, Jassem E, et al. Gene expression analysis in 
predicting the effectiveness of insect venom immunotherapy. J Allergy Clin Immunol. 2010;125(5):1092-7.

7. Niedoszytko M, Bruinenberg M, de Monchy J, Weersma RK, Wijmenga $C$, Jassem $E$, et al. Changes in gene expression caused by insect venom immunotherapy responsible for the long-term protection of insect venom-allergic patients. Ann Allergy Asthma Immunol. 2011;106(6):502-10.

8. Niedoszytko M, Gruchała-Niedoszytko M, Jassem $E$. Gene expression analysis in allergology: the prediction of Hymenoptera venom allergy severity and treatment efficacy. Clin Transl Allergy. 2013;3(1):35.

9. Niedoszytko M, Bonadonna P, Oude Elberink JN, Golden DB. Epidemiology, diagnosis, and treatment of Hymenoptera venom allergy in mastocytosis patients. Immunol Allergy Clin North Am. 2014;34(2):365-81.

10. Keller $A$, Leidinger $P$, Bauer $A$, Elsharawy $A$, Haas J, Backes $C$, et al. Toward the blood-borne miRNome of human diseases. Nat Methods. 2011;8(10):841-3.

11. Leidinger $P$, Backes $C$, Meder B, Meese $E$, Keller A. The human miRNA repertoire of different blood compounds. BMC Genomics. 2014;15:474.

12. Keller $A$, Leidinger $P$, Vogel $B$, Backes $C$, ElSharawy $A$, Galata $V$, et al. miRNAs can be generally associated with human pathologies as exemplified for miR-144. BMC Med. 2014; 12:224.

13. Ludwig $N$, Leidinger $P$, Becker $K$, Backes $C$, Fehlmann $T$, Pallasch $C$, et al. Distribution of miRNA expression across human tissues. Nucleic Acids Res. 2016;44(8):3865-77.

14. Hart M, Rheinheimer $S$, Leidinger $P$, Backes $C$, Menegatti J, Fehlmann T, et al. Identification of miR-34a-target interactions by a combined network based and experimental approach. Oncotarget. 2016;7(23):34288-99.

15. Backes C, Meese $E$, Keller A. Specific miRNA Disease Biomarkers in Blood, Serum and Plasma: Challenges and Prospects. Mol Diagn Ther. 2016;20(6):509-18.

16. Backes C, Kehl T, Stöckel D, Fehlmann T, Schneider L, Meese E, et al. miRPathDB: a new dictionary on microRNAs and target pathways. Nucleic Acids Res. 2017;45(D1):D90-D96.

17. Backes C, Fehlmann T, Kern F, Kehl T, Lenhof HP, Meese E, et al. miRCarta: a central repository for collecting miRNA candidates. Nucleic Acids Res. 2018;46(D1):D160-D167.

18. Dissanayake $E$, Inoue Y. MicroRNAs in Allergic Disease. Curr Allergy Asthma Rep. 2016;16(9):67.

19. Specjalski K, Maciejewska A, Pawłowski R, Chełmińska M, Jassem E. Changes in the Expression of MicroRNA in the Buildup Phase of Wasp Venom Immunotherapy: A Pilot Study. Int Arch Allergy Immunol. 2016;170(2):97-100.
20. López-Romero P. Pre-processing and differential expression analysis of Agilent microRNA arrays using the AgiMicroRna Bioconductor library. BMC Genomics. 2011;12:64.

21. Graffelman J, van Eeuwijk F. Calibration of multivariate scatter plots for exploratory analysis of relations within and between sets of variables in genomic research. Biom J. 2005;47(6):86379.

22. Pfaffl MW, Horgan GW, Dempfle L. Relative expression software tool (REST) for group-wise comparison and statistical analysis of relative expression results in real-time PCR. Nucleic Acids Res. 2002;30(9):e36.

23. Newman AM, Liu CL, Green MR, Gentles AJ, Feng W, Xu Y, et al. Robust enumeration of cell subsets from tissue expression profiles. Nat Methods. 2015;12(5):453-7.

24. Shen-Orr SS, Tibshirani R, Khatri P, Bodian DL, Staedtler F, Perry $\mathrm{NM}$, et al. Cell type-specific gene expression differences in complex tissues. Nat Methods. 2010;7(4):287-9.

25. Reynaud CA, Weill JC. Gene profiling of CD11 b+ and CD11 bB1 cell subsets reveals potential cell sorting artifacts. J Exp Med. 2012;209(3):433-4.

26. Bukowska-Straková K, Baran J, Gawlicka M, Kowalczyk D. A false expression of CD8 antigens on CD4+ T cells in a routine flow cytometry analysis. Folia Histochem Cytobiol. 2006;44(3):179-83.

27. Gaujoux R, Seoighe C. CellMix: a comprehensive toolbox for gene expression deconvolution. Bioinformatics. 2013;29(17):2211-2.

28. Schuerwegh AJ, De Clerck LS, Bridts CH, Stevens WJ. Wasp venom immunotherapy induces a shift from IL-4-producing towards interferon-gamma-producing CD4+ and CD8+ T lymphocytes. Clin Exp Allergy. 2001;31(5):740-6.

Manuscript received April 14, 2018; accepted for publication August 16, 2018.

\section{— Pawel Karpinski}

Department of Genetics

Wroclaw Medical University

ul. Marcinkowskiego 1

50-368 Wroclaw, Poland

E-mail: polemiraza@poczta.fm 